\title{
ПРОСТРАНСТВЕННЫЙ АНАЛИЗ МЕЖРЕГИОНАЛЬНОЙ ДИФФЕРЕНЦИАЦИИ РОССИЙСКОГО РЫНКА ТРУДА"
}

\author{
(c) 2021 Толмачев Михаил Николаевич \\ доктор экономических наук, профессор Департамента бизнес-аналитики \\ Финансовый университет при Правительстве Российской Федерации, Россия, Москва \\ E-mail:MNTolmachev@fa.ru \\ (c) 2021 Никифорова Елена Владимировна \\ доктор экономических наук, профессор Департамента бизнес-аналитики \\ Финансовый университет при Правительстве Российской Федерации, Россия, Москва \\ E-mail: EVNikiforova@fa.ru
}

В работе рассматривается влияние пространственного фактора на региональные уровни безработицы Российской Федерации. На основе сравнительного анализа моделей показана оптимальность разбиения регионов на западный и восточный кластеры. Наиболее приемлемым вариантом при анализе безработицы представляется предварительное разбиение регионов на два пространственных кластера, граница которых совпадает с границей Уральского и Сибирского федеральных округов. Сделан вывод о значимости влияния на безработицу уровня развития малого бизнеса и доступности жилья. Установлено, что на региональные рынки труда европейской части страны дополнительное влияние оказывают структурные факторы, в первую очередь доля государственного управления в валовом региональном продукте.

Ключевые слова: безработица, регионы России, панельный анализ, пространственный фактор

\section{Введение}

При анализе уровня безработицы в России обращает на себя внимание весьма высокий уровень региональной неоднородности. Так, в 2020 г. минимальный уровень безработицы был зафиксирован в Ямало-Ненецком автономном округе (2,4\%), а максимальный - в Республике Ингушетия (30,0\%). При этом заметной региональной дивергенции по данному показателю не наблюдается: в период 2001-2020 гг. коэффициент вариации был устойчиво выше 50\%, с пиками в 2006 г. (104\%) и 2012 г. (83\%).

В работе [1] отмечают, что национальные рынки труда в большинстве стран, включая Россию, отреагировали на covid-кризис не только спадом занятости и повышением уровня безработицы, но и уменьшением рабочего времени, снижением уровня оплаты труда, отменой выплат премий.

Другой заслуживающий внимания фактор наличие пространственных эффектов, достаточно убедительно доказанное в работах [9] и [5]. Идея разбиения страны на два крупных кластера («Север» - «Юг» или «Запад» - «Восток») достаточно популярна в эконометрических моделях $[7,8]$. В российской практике, вероятно, впервые она была реализована в работе [3], где анализировались влияние пространственных эффектов на рост ВРП. При этом проводилось разбиение регионов России на два кластера - западный и восточный. Учитывая резкие различия между регионами европейской и азиатской части страны, такое разбиение представляется обоснованным. Достаточно успешный пример пространственного анализа безработицы представлен в работе [9]. В то же время обращает на себя внимание несколько искусственный характер отбора факторных показателей (доля лиц с высшим образованием, душевой уровень ВРП и пр.), не имеющий достаточного экономического обоснования.

Тем не менее, пространственный автокорреляционный анализ имеет свои ограничения, связанные, в первую очередь, с излишней «грубостью» моделирования межрегиональных экономических связей при помощи взвешивающей матрицы, как правило, опирающейся на расстояние между центрами регионов [6]. Кроме того, излишнее внимание к пространственному фактору (т.е. влиянию на безработицу в конкретном регионе уровней безработицы во всех остальных регионах России) в большинстве случае пред-

* Исследование выполнено при финансовой поддержке РФФИ в рамках научного проекта № 20-010-00681. 
ставляется явно избыточным, «затмевающим» влияние других факторов и искажающим оценки коэффициентов модели.

Оптимальным решением, на наш взгляд, является учет пространственного фактора при помощи сравнительно простого показателя «расстояние до Москвы», который уже использовался в работах [2] и [4]. Российская экономика является высокоцентрализованной не только в институциональном, но и в географическом плане. Это подразумевает высокий уровень концентрации финансовых, интеллектуальных и иных видов ресурсов в столице, которая одновременно является крупнейшим транспортным узлом.

Таким образом, выдвигается гипотеза о целесообразности построения двух отдельных эконометрических моделей безработицы: отдельно для западных и восточных регионов страны.

\section{Основные результаты}

Проверим предположение о наличии двух пространственных кластеров (западного и восточного), граница между которыми является границей Уральского и Сибирского федеральных округов. К кластеру «Запад», таким образом, относятся 64 региона, к кластеру «Восток» -21 регион (табл. 1).

Корреляция между уровнем безработицы в регионах восточного кластера и расстоянием до Москвы является устойчиво отрицательной, что нивелирует роль этого фактора при изучении безработицы для всех российских регионов. Однако, при рассмотрении только «западных» регионов, этот фактор приобретает заметный вес. Что касается кластера «Восток», роль пространственного фактора (расстояние до Владивостока) пока не является статистически значимой, однако динамика коэффициента корреляции свидетельствует о постепенном росте влияния географической составляющей на уровень безработицы в Сибири и на Дальнем Востоке. При этом обращает на себя внимание нарастающая положительная связь с расстояниями до Москвы и Владивостока. Это косвенно указывает на сравнительно неблагоприятную ситуацию с безработицей в сибирских регионах (от Курганской области на западе до Забайкальского края на востоке), одинаково удаленных от более благополучных в этом плане «окраин» страны.

Таким образом, можно выдвинуть предположение о влиянии географического положения региона (на западе или на востоке) на уровень безработицы. Однако наличие корреляционной связи не означает наличия обусловленности. Возникают два вопроса:

1) является ли расстояние до Москвы самостоятельным фактором безработицы в западной части страны (например, с точки зрения сложности трудовой миграции из регионов) или же этот показатель лишь коррелирует с другими (фоновыми) факторами?

2) целесообразно ли использование в анализе (в том числе панельном) фиктивной переменной, обозначающей принадлежность региона к западному или восточному кластеру?

Прежде чем попытаться ответить на эти вопросы, рассмотрим другой аспект проблемы - влияние отраслевой структуры региональной экономики на уровень безработицы. Иными словами, поставим вопрос о наличии отраслей, которые могут рассматриваться как «драйверы» безработицы на региональном уровне. Наиболее простой и очевидный путь - оценка тесноты связи между уровнем безработицы в регионе и долей соответствующей отрасли в ВРП за предыдущий год. В рамках проверки гипотезы о

Таблица 1. Динамика коэффициентов корреляции между уровнем безработицы и расстоянием от центра региона до Москвы и Владивостока (выделены коэффициенты, значимые при $\alpha=0,05$ )

\begin{tabular}{|c|c|c|c|}
\hline Год & $\begin{array}{c}\text { Расстояние до Москвы } \\
\text { (все регионы) }\end{array}$ & $\begin{array}{c}\text { Расстояние до Москвы } \\
\text { («Запад») }\end{array}$ & $\begin{array}{c}\text { Расстояние до Владивостока } \\
\text { («Восток») }\end{array}$ \\
\hline 2000 & $\mathbf{0 , 2 8 5 0}$ & $\mathbf{0 , 4 2 3 8}$ & $-0,0119$ \\
\hline 2005 & 0,0842 & $\mathbf{0 , 3 6 0 8}$ & 0,1230 \\
\hline 2010 & 0,0775 & $\mathbf{0 , 3 7 2 1}$ & $-0,0255$ \\
\hline 2015 & 0,1616 & $\mathbf{0 , 4 6 1 8}$ & 0,1030 \\
\hline 2016 & 0,1558 & $\mathbf{0 , 4 5 3 6}$ & 0,1675 \\
\hline 2017 & 0,1788 & $\mathbf{0 , 4 7 8 7}$ & 0,0821 \\
\hline 2018 & 0,1780 & $\mathbf{0 , 4 6 4 5}$ & 0,1332 \\
\hline 2019 & 0,1573 & $\mathbf{0 , 4 5 5 6}$ & 0,1540 \\
\hline 2020 & 0,1114 & $\mathbf{0 , 4 4 9 5}$ & 0,2997 \\
\hline
\end{tabular}


значимости различий между моделями безработицы «Запада» и «Востока», рассчитаем соответствующие индикаторы отдельно для двух территориальных кластеров (рис. 1-2).

Основными драйверами снижения безработицы в регионах «Запада» являются виды экономической деятельности (ВЭД) С («Обрабатывающие производства»), М («Деятельность профессиональная, научная и техническая»), N («Деятельность административная и сопутствующие дополнительные услуги») и К («Деятельность финансовая и страховая»). Нужно отметить, что ввиду крайне малых (а зачастую и нулевых) значений удельного веса ВЭД К в регионах, ее влияние на уровень безработицы весьма сомнительно. С другой стороны, высокий удельный вес таких ВЭД, как торговля (код $\mathrm{G)}$ и добыча полезных ископаемых (код В) даже при небольших абсолютных значениях коэффициента корреляции могут оказывать влияние на уровень безработицы. При этом нужно учитывать, что доля ВЭД В и G тесно связаны друг с другом. С точки зрения построения модели более привлекательным выглядит фактор G, который, в отличие от В, гораздо слабее связан с другими факторными признаками.

Доля ВЭД L («Деятельность по операциям с недвижимым имуществом») с 2019 г. не оказывает значимого влияния на безработицу. Возможно, это связано с резким ростом данного показателя (с 6,5\% до 10\% в целом по РФ), обу- словленного изменениями в методологии или иными причинами.

Немалый интерес представляет наличие шести ВЭД, имеющих значимую положительную связь с уровнем безработицы. Это А («Сельское, лесное хозяйство, охота, рыболовство и рыбоводство»), F («Строительство»), О («Государственное управление и обеспечение военной безопасности; социальное обеспечение»), Р («Образование»), Q («Деятельность в области здравоохранения и социальных услуг») и R («Деятельность в области культуры, спорта, организации досуга и развлечений»). При этом доли последних четырех ВЭД весьма сильно коррелируют друг с другом, что объясняется доминирующей долей государственного участия в этих отраслях.

Отраслевая картина в кластере «Восток» (рис. 2) несколько отличается от «западной» модели. Во-первых, здесь полностью отсутствуют отрасли-драйверы снижения безработицы (точнее, их влияние на уровень безработицы не значимо). В частности, отсутствие значимого воздействия обрабатывающей промышленности (ВЭД С) может быть обусловлено сравнительно низким уровнем ее развития в Сибири и на Дальнем Востоке. В восточных регионах страны выше негативное воздействие на безработицу доли здравоохранения и образования (ВЭД Р и Q) и ниже - влияние государственного управления (ВЭД О) и деятельности в области культуры и спорта (ВЭД R).

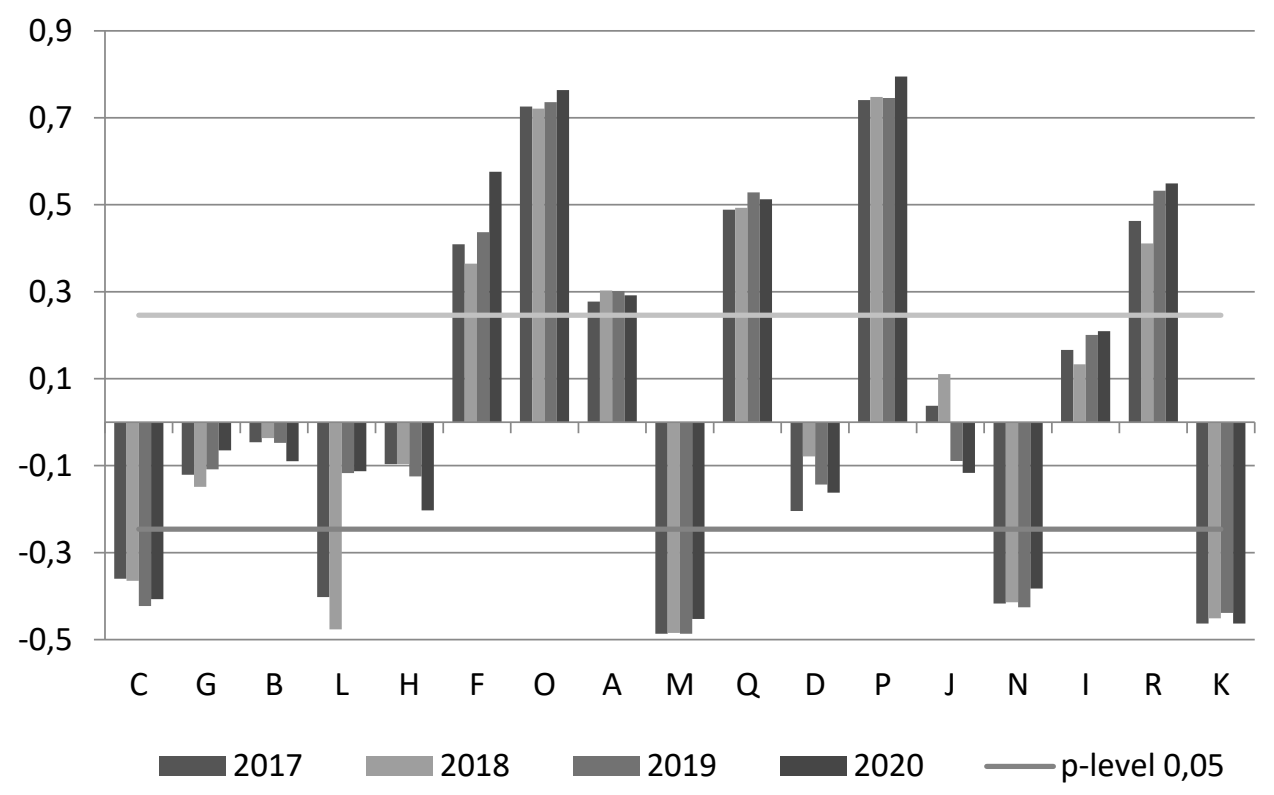

Рисунок 1. Динамика коэффициентов корреляции между уровнем безработицы и долей ВЭД в ВРП регионов «Запада», 2017-2020 годы (отрасли кодированы в соответствии с ОКВЭД-2 и упорядочены по убыванию их доли в ВВП России) 


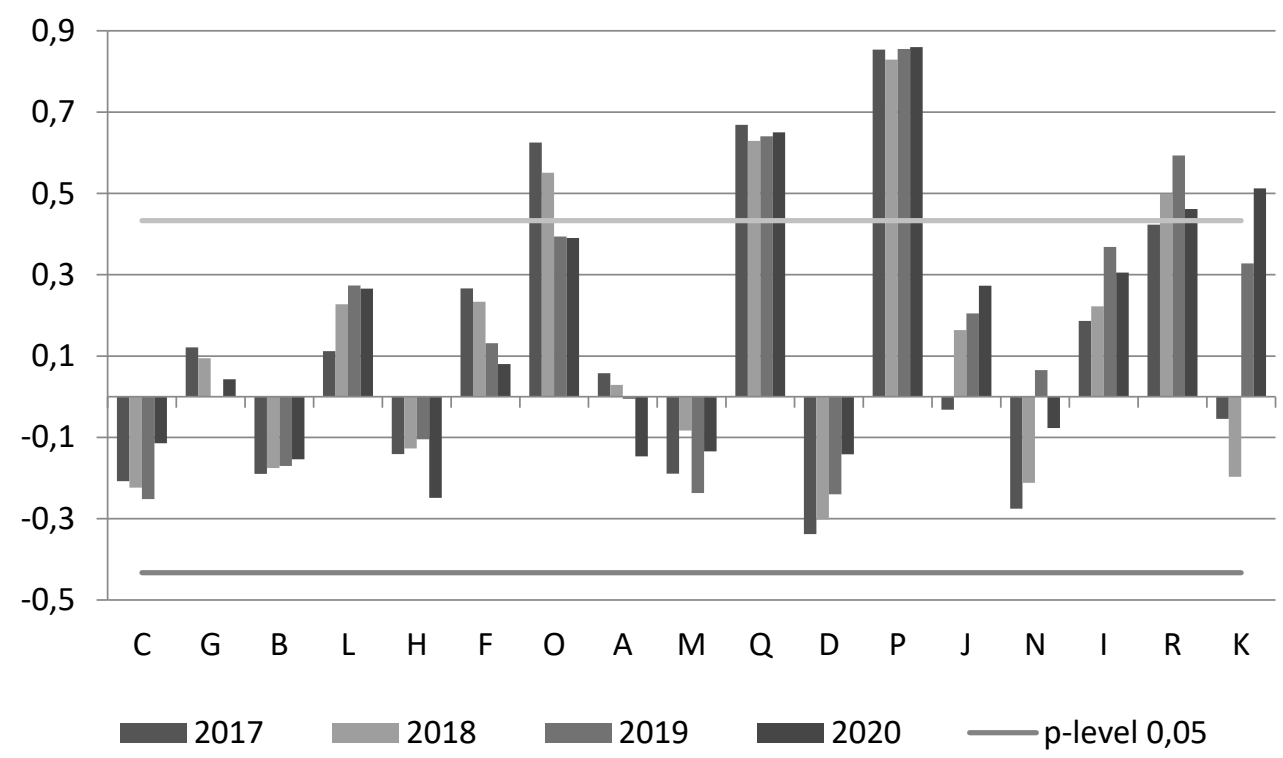

Рисунок 2. Динамика коэффициентов корреляции между уровнем безработицы и долей Вэд в ВРП регионов «Востока», 2017-2020 годы

Таким образом, к отраслям, потенциально влияющим на уровень безработицы, можно отнести, в первую очередь, ВЭД с кодами C, G, O, $\mathrm{P}, \mathrm{Q}, \mathrm{R}$. Ввиду сильной коррелированности последних четырех отраслей в качестве фактора была выбрана доля отрасли О («Государственное управление и обеспечение военной безопасности; социальное обеспечение») в ВРП как наиболее показательная с точки зрения присутствия госсектора в экономике региона.

К другим факторам, отобранным для использования в регрессионных моделях, относятся:

$\mathrm{S}$ - уровень развития малого бизнеса (удельный вес занятых в малом бизнесе в численности занятого населения);

$\mathrm{W}$ - уровень доступности жилья (отношение средней заработной платы к средней цене 1 кв.м. жилья на вторичном рынке).

Исходные значения были предварительно логарифмированы с целью снижения риска гетероскедастичности и улучшения качества моделей.

Рассмотрим наиболее показательные модели безработицы в 2017 и 2020 годах. В табл. 2 и 3 приведены параметры регрессионных моделей, исправленный $\mathrm{R}^{2}$ и результат $\chi^{2}$-тестирования на адекватность модели (проверка нулевой гипотезы о нормальном распределении остатков). Помимо этого, модели проверялись на возможное наличие гетероскедастичности. В тех случаях, когда тест Уайта (White test) отклонял нулевую гипотезу о гомоскедастичности ошибок, при оценивании параметров делалась поправка на гетероскедастичность.

Отсутствие в модели «Восток» факторов G (доля ВЭД «Торговля оптовая и розничная; ремонт автотранспортных средств и мотоциклов») и О (доля ВЭД «Государственное управление и

Таблица 2. Параметры региональных моделей безработицы (Россия, кластеры «Запад» и «Восток») за 2017 год

\begin{tabular}{|c|c|c|c|c|c|c|}
\hline \multirow{2}{*}{ Показатель } & \multicolumn{2}{|c|}{ Россия в целом } & \multicolumn{2}{|c|}{ «Запад» } & \multicolumn{2}{|c|}{ «Восток» } \\
\hline & коэф-т & p-значение & коэф-т & p-значение & коэф-т & p-значение \\
\hline const & 2,9917 & 0,0000 & 3,2308 & 0,0000 & 2,8584 & 0,0000 \\
\hline $\ln S$ & $-0,4959$ & 0,0000 & $-0,5592$ & 0,0000 & $-0,4557$ & 0,0036 \\
\hline $\ln W$ & $-0,6340$ & 0,0000 & $-0,7992$ & 0,0000 & $-0,7681$ & 0,0001 \\
\hline $\ln G$ & $-0,2972$ & 0,0000 & $-0,3107$ & 0,0000 & - & - \\
\hline $\ln \mathrm{O}$ & 0,1564 & 0,0000 & 0,1641 & 0,0114 & - & - \\
\hline adjusted $\mathrm{R}^{2}$ & \multicolumn{2}{|c|}{0,7430} & \multicolumn{2}{|c|}{0,8655} & \multicolumn{2}{|c|}{0,5793} \\
\hline$\chi^{2}$ & 3,7678 & 0,1512 & 1,1497 & 0,5628 & 1,6491 & 0,4384 \\
\hline White test & 25,8321 & 0,0272 & 38,6544 & 0,0001 & 0,0355 & 0,0742 \\
\hline
\end{tabular}


Таблица 3. Параметры региональных моделей безработицы (Россия, кластеры «Запад» и «Восток») за 2020 год

\begin{tabular}{|l|c|c|c|c|c|c|}
\hline \multirow{2}{*}{ Показатель } & \multicolumn{2}{|c|}{ Россия в целом } & \multicolumn{2}{c|}{ «Запад» } & \multicolumn{2}{c|}{ «Восток» } \\
\cline { 2 - 7 } & коэф-т & р-значение & коэф-т & р-значение & коэф-т & р-значение \\
\hline const & 2,7272 & 0,0000 & 3,0216 & 0,0000 & 3,4102 & 0,0000 \\
\hline $\ln S$ & $-0,5196$ & 0,0000 & $-0,5951$ & 0,0000 & - & - \\
\hline $\ln \mathrm{W}$ & $-0,3511$ & 0,0019 & $-0,4422$ & 0,0000 & $-1,3694$ & 0,0000 \\
\hline $\ln \mathrm{C}$ & - & - & - & - & $-0,2020$ & 0,0016 \\
\hline $\ln \mathrm{G}$ & $-0,11185$ & 0,0283 & $-0,1299$ & 0,0118 & $-0,4617$ & 0,0236 \\
\hline $\ln \mathrm{C}$ & 0,2428 & 0,0007 & 0,2028 & 0,0004 & - & - \\
\hline adjusted $\mathrm{R}^{2}$ & \multicolumn{2}{|c|}{0,7187} & \multicolumn{2}{c|}{0,7110} & \multicolumn{2}{c|}{0,6159} \\
\hline$\chi^{2}$ & 5,9796 & 0,0503 & 6,4632 & 0,0395 & 2,2051 & 0,3320 \\
\hline White test & 37,5420 & 0,0006 & 3,3647 & 0,0026 & 11,1794 & 0,2636 \\
\hline
\end{tabular}

обеспечение военной безопасности; социальное обеспечение») объясняется незначимостью соответствующих коэффициентов, значения которых (-0,27 и 0,11 соответственно) весьма близки к общероссийским.

Обращает на себя внимание пространственная стабильность фактора S в 2017 г. С ростом доли занятых в малом бизнесе на $1 \%$ безработица в относительном выражении снижалась в среднем на $0,46 \% . . .0,56 \%$.

Фактор W оказался единственным, значимым во всех моделях за оба рассматриваемых периода. Рост доступности жилья на $1 \%$ приводил к снижению безработицы в среднем на 0,35\%-1,37\%. В европейской части страны этот эффект был слабее, а в Сибири и на Дальнем Востоке - сильнее.

Важнейшим из факторов, отражающих региональную структуру ВРП, оказался фактор государственного участия в экономике, представленный переменной О. Чем выше доля ВЭД «Государственное управление и обеспечение военной безопасности; социальное обеспечение» в региональном продукте, тем выше уровень безработицы. Так, республики Ингушетия, Чечня, Алтай, Калмыкия и Тыва стабильно входят в число лидеров по обоим показателям. Можно предположить, что высокий удельный вес ВЭД «Государственное управление и обеспечение военной безопасности; социальное обеспечение» обусловлен в первую очередь, низким уровнем диверсификации региональной экономики и является своеобразным индикатором экономически слабо развитых и дотационных регионов. Это подтверждается и не слишком тесной, но стабильной и статистически значимой отрицательной связью между данным показателем и душевым ВРП в постоянных ценах (коэффициент корреляции за 2015-2019 гг. колеблется в пределах $-0,32 \ldots-0,36)$.

Попытаемся оценить модели безработицы для европейской части страны, явно учитывающие расстояние до Москвы (DIST). Ввиду сильной корреляции между расстоянием до столицы и уровнем развития малого бизнеса последний фактор в модель включить невозможно. Совместное включение параметров О и W также не дало удовлетворительных результатов: в данном случае эти факторы можно рассматривать как конкурирующие. В связи с этим были построены два варианта модели, включающие параметры О и W по отдельности (табл. 4).

Для всех четырех моделей наблюдалась гетероскедастичность остатков, поэтому оценивание параметров велось с учетом этого обстоятельства. Несмотря на то, что влияние факторов О и W на уровень безработицы является разнонаправленным, значения коэффициентов при DIST оказались достаточно стабильными: увеличение расстояния от центра региона до столицы на 1\% в среднем повышало уровень безработицы на 0,13\%-0,16\%. Влияние параметра О на безработицу в западных регионах страны явно более весомо, нежели влияние параметра W, в отличие от Сибири и Дальнего Востока, где первый параметр оказался незначимым (см. табл. 2-3).

Рассмотрим аналогичные панельные модели за период 2017-2020 гг. Сильное влияние на безработицу оказывает фактор В (доля ВЭД «Добыча полезных ископаемых»), однако он сильно коррелирует с доступностью жилья и удельным весом ВЭД «Торговля оптовая и розничная; ремонт автотранспортных средств и мотоциклов». 
Таблица 4. Параметры двухфакторных региональных моделей безработицы (Россия, кластер «Запад»)

\begin{tabular}{|c|c|c|c|c|}
\hline \multirow{2}{*}{ Показатель } & \multicolumn{2}{|c|}{2017 год } & \multicolumn{2}{|c|}{2020 год } \\
\hline & коэф-Т & p-значение & коэф-т & p-значение \\
\hline \multicolumn{5}{|c|}{ Модель 1} \\
\hline const & $-0,2736$ & 0,2117 & 0,0766 & 0,7994 \\
\hline lnDIST & 0,1652 & 0,0000 & 0,1454 & 0,0003 \\
\hline $\operatorname{lnO}$ & 0,4779 & 0,0000 & 0,3937 & 0,0000 \\
\hline adjusted $\mathrm{R}^{2}$ & \multicolumn{2}{|c|}{0,5293} & \multicolumn{2}{|c|}{0,3241} \\
\hline$\chi^{2}$ & 19,2594 & 0,0000 & 11,0326 & 0,0040 \\
\hline White test & 21,5569 & 0,0006 & 11,4058 & 0,0439 \\
\hline \multicolumn{5}{|c|}{ Модель 2} \\
\hline const & 0,4322 & 0,0451 & 0,7883 & 0,0000 \\
\hline lnDIST & 0,1467 & 0,0001 & 0,1327 & 0,0001 \\
\hline $\ln W$ & $-0,5180$ & 0,0016 & $-0,3429$ & 0,0321 \\
\hline adjusted $\mathrm{R}^{2}$ & \multicolumn{2}{|c|}{0,3610} & \multicolumn{2}{|c|}{0,3268} \\
\hline$\chi^{2}$ & 10,3463 & 0,0057 & 14,733 & 0,0006 \\
\hline White test & 12,7004 & 0,0264 & 16,6275 & 0,0053 \\
\hline
\end{tabular}

В связи с этим указанный фактор был исключен из рассмотрения. Дополнительно рассматривалась фиктивная переменная WEST, принимающая значение «1» для западных регионов и «0»для восточных.

Традиционно в панельном анализе рассматриваются три основные модели:

1) объединенная модель (pooled model), в которой отсутствует дифференциация в пространстве и времени;

2) модель с фиксированными эффектами (FEM, рассматривающая отклонения от среднего значения за период для каждого объекта);

3) модель со случайными эффектами (REM, предполагающая наличие постоянной во времени компоненты ошибки, специфической для каждого объекта).

Каждая из моделей обладает своим набором достоинств и недостатков. Например, в FEM невозможно оценить неизменные во времени переменные, такие как WEST. Выбор одной из моделей осуществляется при помощи нескольких тестов: тест Вальда (Wald test), проверяющий нулевую гипотезу об отсутствии пространственной гетерогенности (pooled model против FEM); тест Бройша-Пагана (Breusch-Pagan test) о равенстве нулю специфической компоненты ошибки (pooled model против REM); асимптотический тест Хаусмана (Hausman test) о состоятельности оценок модели со случайными эффектами (FEM против REM). B качестве дополнительных параметров качества модели рассматривались зна- чения функции правдоподобия (Log-likelihood function) и байесовского информационного критерия (ВIC) (табл. 5-6).

Обращает на себя внимание близость оценок объединенной модели и модели с фиксированными эффектами (учитывая отсутствие в последней фиктивной переменной WEST). Отклонения оценок модели со случайными эффектами также незначительны, за исключение факторов W и G. Тест Хаусмана отклоняет гипотезу о состоятельности REM-оценок на уровне значимости 0,05 , а значение F-статистики (Wald test) говорит о наличии пространственных эффектов, т.е. большей предпочтительности FEM по сравнению с объединенной моделью.

Сравнивая результаты оценивания моделей панельных данных с учетом и без учета пространственного фактора, можно прийти к выводу о том, что первые в целом являются более качественными.

\section{Заключение}

На основе проведенных расчетов можно сделать следующие выводы. Результаты моделирования показывают, что уровень безработицы в регионах подвержен влиянию пространственного фактора, однако это влияние можно считать опосредованным. В частности, сильная корреляция безработицы в европейской части страны от расстояния до Москвы обусловлена, скорее, зависимостью последнего показателя с уровнем развития малого бизнеса. Действительно, успеш- 
Таблица 5. Параметры пятифакторных моделей панельных данных с учетом пространственного фактора (Россия, 2017-2020 гг.)

\begin{tabular}{|c|c|c|c|c|c|c|}
\hline \multirow{2}{*}{ Показатель } & \multicolumn{2}{|c|}{ Pooled model } & \multicolumn{2}{|c|}{ FEM } & \multicolumn{2}{|c|}{ REM } \\
\hline & коэф-Т & p-значение & коэф-т & p-значение & коэф-т & p-значение \\
\hline const & 3,1314 & 0,0000 & 2,9016 & 0,0000 & 2,9650 & 0,0000 \\
\hline WEST & $-0,2505$ & 0,0000 & - & - & $-0,2162$ & 0,0008 \\
\hline $\ln S$ & $-0,5107$ & 0,0000 & $-0,4886$ & 0,0000 & $-0,5279$ & 0,0000 \\
\hline $\ln W$ & $-0,7566$ & 0,0000 & $-0,8252$ & 0,0000 & $-0,5463$ & 0,0000 \\
\hline $\ln G$ & $-0,2276$ & 0,0000 & $-0,2178$ & 0,0000 & $-0,1082$ & 0,0239 \\
\hline $\operatorname{lnO}$ & 0,1908 & 0,0000 & 0,2408 & 0,0000 & 0,1659 & 0,0004 \\
\hline adjusted $\mathrm{R}^{2}$ & \multicolumn{2}{|c|}{0,6918} & \multicolumn{2}{|c|}{0,6776} & \multicolumn{2}{|c|}{ - } \\
\hline$\chi^{2}$ & 3,3741 & 0,1851 & 1,4459 & 0,4853 & 10,7965 & 0,0045 \\
\hline Wald test & 13,8750 & 0,0000 & & & & \\
\hline Breusch-Pagan test & 261,621 & 0,0000 & & & & \\
\hline Hausman test & 35,1341 & 0,0000 & & & & \\
\hline Log-likelihood & \multicolumn{2}{|c|}{$-13,7375$} & \multicolumn{2}{|c|}{278,7723} & \multicolumn{2}{|c|}{$-26,6911$} \\
\hline BIC & \multicolumn{2}{|c|}{62,4469} & \multicolumn{2}{|c|}{$-38,7652$} & \multicolumn{2}{|c|}{88,3558} \\
\hline
\end{tabular}

Таблица 6. Параметры четырехфакторных моделей панельных данных без учета пространственного фактора (Россия, 2017-2020 гг.)"

\begin{tabular}{|c|c|c|c|c|c|c|}
\hline \multirow{2}{*}{ Показатель } & \multicolumn{2}{|c|}{ Pooled model } & \multicolumn{2}{|c|}{ FEM } & \multicolumn{2}{|c|}{ REM } \\
\hline & коэф-т & p-значение & коэф-т & p-значение & коэФ-т & p-значение \\
\hline const & 2,7964 & 0,0000 & 2,9016 & 0,0000 & 2,7049 & 0,0000 \\
\hline $\ln S$ & $-0,4772$ & 0,0000 & $-0,4886$ & 0,0000 & $-0,5080$ & 0,0000 \\
\hline $\ln W$ & $-0,6227$ & 0,0000 & $-0,8252$ & 0,0000 & $-0,4740$ & 0,0000 \\
\hline $\ln G$ & $-0,2540$ & 0,0000 & $-0,2178$ & 0,0000 & $-0,1006$ & 0,0428 \\
\hline $\operatorname{lnO}$ & 0,2775 & 0,0000 & 0,2408 & 0,0000 & 0,1924 & 0,0000 \\
\hline adjusted $\mathrm{R}^{2}$ & \multicolumn{2}{|c|}{0,6501} & \multicolumn{2}{|c|}{0,6776} & \multicolumn{2}{|c|}{ - } \\
\hline$\chi^{2}$ & 5,8419 & 0,0539 & 1,4459 & 0,4853 & 9,6468 & 0,0080 \\
\hline Wald test & 13,8750 & 0,0000 & & & & \\
\hline Breusch-Pagan test & 289,588 & 0,0000 & & & & \\
\hline Hausman test & 31,6148 & 0,0000 & & & & \\
\hline Log-likelihood & \multicolumn{2}{|c|}{$-35,8395$} & \multicolumn{2}{|c|}{278,7723} & \multicolumn{2}{|c|}{$-48,8629$} \\
\hline BIC & \multicolumn{2}{|c|}{100,8236} & \multicolumn{2}{|c|}{$-38,7652$} & \multicolumn{2}{|c|}{126,8705} \\
\hline
\end{tabular}

* Результаты оценивания по FЕМ для четырехфакторной модели совпадают с пятифакторной, ввиду невозможности учета в ее рамках неизменной во времени переменной WEST.

ность ведения малого бизнеса (бо́льшую часть которого в России представляют организации, занимающиеся оптовой и розничной торговлей) серьезно зависит от времени и стоимости транспортировки товаров. По-видимому, в условиях сравнительно низкой транспортной связности, высокой стоимости транспортных услуг и сверхцентрализации финансовых и иных ресурсов (сосредоточенных в столице) расстояние до Москвы играет весьма важную роль в формировании переменных издержек значительной части предприятий малого бизнеса. Примером может служить тот факт, что почти все товары из ЕС и КНР попадают в европейские регионы страны через Москву. Однако, с увеличением расстояния транспортные издержки малого бизнеса в восточной части страны возрастают настолько, что выгоднее импортировать товары напрямую из КНР, минуя Москву, что нивелирует рассматриваемую взаимосвязь.

В связи с этим, наиболее приемлемым вариантом при анализе безработицы представляет- 
ся предварительное разбиение регионов на два пространственных кластера, граница которых совпадает с границей Уральского и Сибирского федеральных округов. Данное предположение подтверждается и сравнением моделей панельного анализа с наличием и отсутствием соответствующей фиктивной переменной WEST.

Помимо уровня развития малого бизнеса, другим важным фактором безработицы является доступность жилья. В рассмотренных моделях коэффициент эластичности по данному параметру колебался в пределах $-0,35 . . .-0,8$. Рост доступности жилья одновременно повышает доступность аренды недвижимости (в том числе коммерческой), что благоприятно сказывается на привлекательности региона для рабочей силы и бизнеса.

Анализ влияния структуры ВРП на безработицу затруднен значительными различиями российских регионов, обусловленными их «специализацией»: доминированием сельскохозяйственной, добывающей, обрабатывающей и иных отраслей. В связи с этим в моделях рассматривались лишь наиболее «универсальные» виды экономической деятельности, занимающие сравнительно устойчивый вес в структуре валового продукта: торговля, государственное управление, образование, здравоохранение и культура. Однако одновременное включение в модель последних четырех ВЭД невозможно ввиду мультиколлинеарности. По сути, все они отражают степень государственного участия в региональной экономике. В связи с этим был выбран один, наиболее характерный показатель: доля ВЭД «Государственное управление и обеспечение военной безопасности; социальное обеспечение». Эластичность данного показателя в моделях изменялась от 0,16 до 0,48. По всей видимости, значительная степень участия в экономике тесно аффилированных с государством институциональных единиц является важным признаком неблагополучия региона, что проявляется, в частности, в высоком уровне безработицы.

При сравнении моделей, построенных для кластеров «Запад» и «Восток», обращает на себя внимание тот факт, что влияние государственного сектора на безработицу гораздо сильнее проявляется в европейской части страны. Это же касается доли ВЭД «Торговля оптовая и розничная; ремонт автотранспортных средств и мотоциклов». По всей видимости, безработица в сибирских и дальневосточных регионах зависит от несколько иного (нежели рассмотренный) набора факторов, что еще раз подтверждает необходимость пространственной дифференциации регионов России при анализе безработицы.

\section{Библиографический список}

1. Блинова Т.В., Русановский В.А., Марков В.А. Оценка влияния экономических колебаний на уровень безработицы в регионах России на основе закона Оукена // Проблемы прогнозирования. - 2021._№ 1 (184). - С. $152-163$.

2. Вакуленко E.С. Анализ связи между региональными рынками труда в России с использованием модели Оукена // Прикладная эконометрика. - 2015. - № 40 (4).-С. 28-48.

3. Коломак Е. А. Пространственные экстерналии как ресурс экономического роста // Регион: экономика и социология. - 2010. - № 4.- С. 73-87.

4. Русановский В.А., Марков В.А. Занятость и производительность труда в макрорегионах России: пространственные взаимосвязи // Проблемы прогнозирования. - 2018. - № 2 (167). - С. 38-48.

5. Семерикова E.В., Демидова О.А. Взаимодействие региональных рынков труда в России: анализ с помощью пространственных эконометрических моделей // Пространственная экономика. - 2016. - № 3. - С. 57-80.

6. Corrado L., Fingleton B. Where is the economics in spatial econometrics? Journal of Regional Science, 2012,52 (2), pp. 210-239.

7. Cracolici M.F., Cuffaro M., Nijkamp P. Geographical distribution of unemployment: An analysis of provincial differences in Italy. Growth and Change, 2007, 38 (4), pp. 649-670.

8. Demidova O.A., Marelli E., Signorelli M. Spatial effects on youth unemployment rate: the case of Eastern and Western Russian regions. Eastern European Economics, 2013, 51 (5), pp. 94-124.

9. Demidova O., Signorelli $M$. The impact of crises on youth unemployment of Russian regions: An empirical analysis. China-USA Business Review, 2010, 10 (7), pp. 491-507. 